\title{
A importância das metodologias 4.0 no desenvolvimento de uma pequena empresa: Estudo de caso sobre a utilização de impressão 3D em uma empresa Metalúrgica
}

The importance of 4.0 methodologies in the development of a small company: Case study on the use of 3D printing in a Metallurgical company

La importancia de las metodologías 4.0 en el desarrollo de una pequeña empresa: Estudio de caso sobre el uso de la impresión 3D en una empresa metalúrgica

Recebido: 20/01/2021 | Revisado: 23/01/2021 | Aceito: 25/01/2021 | Publicado: 27/01/2021

\author{
Marcos de Oliveira Morais \\ ORCID: https://orcid.org/0000-0002-5981-4725 \\ Universidade Estácio de Sá, Brasil \\ Universidade Santo Amaro, Brasil \\ E-mail: marcostecnologia2001@gmail.com \\ Osmildo Sobral dos Santos \\ ORCID: https://orcid.org/0000-0003-3797-5971 \\ Faculdade de Tecnologia de Mauá, Brasil \\ E-mail: osmildosobral@yahoo.com.br \\ Gabriel Alves Morais \\ ORCID: https://orcid.org/0000-0001-5176-4535 \\ Universidade Cruzeiro do Sul, Brasil \\ E-mail: gabriel.moraistecnologia@gmail.com
}

\begin{abstract}
Resumo
A evolução rápida da tecnologia por meio da globalização e abertura dos mercados permite que as empresas possam ser cada vez mais flexíveis em seus processos operacionais e também organizacionais, buscando por um sistema perfeito de produção e de comercialização bem como novos clientes para a sua atuação possibilitando a inclusão em processos inovativos tornando-a competitiva e lucrativa. Objetivo principal do artigo é identificar os elementos principais na implementação de metodologias aplicadas na indústria 4.0. Foi utilizado a metodologia de caso de estudo pelo seu grau de relevância com tema, e pela abrangência que pode ser utilizado de tal maneira que possa ser orientador para outras empresas de micro e pequeno porte que estejam em vias dê ou mesmo aplicando estas metodologias. Os resultados se mostraram positivos para os entrevistados o que reforça a importância do tema.

Palavras-chave: Inovação; Indústria 4.0; Micro e pequena empresa; Impressão 3D.
\end{abstract}

\begin{abstract}
The rapid evolution of technology through globalization and opening of markets allows companies to be increasingly flexible in their operational and also organizational processes, searching for a perfect production and marketing system as well as new customers for their performance, enabling inclusion in innovative processes making it competitive and profitable. The main objective of the article is to identify the main elements in the implementation of methodologies applied in industry 4.0. The case study methodology was used for its degree of relevance with theme, and for the scope that can be used in such a way that it can be a guide for other micro and small companies that are in the process of giving or even applying these methodologies. The results were positive for the interviewees, which reinforces the importance of the theme.
\end{abstract}

Keywords: Innovation; Industry 4.0; Micro and small business; 3D Printing.

\section{Resumen}

La rápida evolución de la tecnología a través de la globalización y apertura de mercados permite a las empresas ser cada vez más flexibles en sus procesos operativos y también organizacionales, buscando un perfecto sistema de producción y comercialización, así como nuevos clientes para su desempeño, posibilitando inclusión en procesos innovadores haciéndola competitiva y rentable. El principal objetivo del artículo es identificar los principales elementos en la implementación de metodologías aplicadas en la industria 4.0. La metodología de estudio de caso se utilizó por su grado de relevancia con la temática, y por el alcance que puede ser utilizado de tal manera que pueda ser una guía para otras micro y pequeñas empresas que se encuentran en proceso de dar o incluso aplicar estas metodologías. Los resultados fueron positivos para los entrevistados, lo que refuerza la importancia del tema.

Palabras clave: Innovación; Industria 4.0; Micro y pequeña empresa; Impresión 3D. 


\section{Introdução}

Com o crescente avanço da manufatura industrial, a competição entre as empresas está crescendo e ficando mais acirrada independentemente de seu porte ou ramo de atuação, superando fronteiras, incentivando novas pesquisas e encorajando o desenvolvimento de tecnologias que buscam agregar valor e otimizar processos produtivos e potencializar recursos humanos, implantando estratégias que proporcionam maior confiabilidade, eficiência e eficácia (Piana \& Erdmann, 2011).

O desenvolvimento tecnológico impulsiona a produtividade industrial, reduzindo custos de produção e fornecendo soluções para o relacionamento com fornecedores e clientes por meio de novos modelos de negócios cada vez mais frequentes (Santos et al., 2018). Diante de um cenário que se torna cada vez com maior complexidade, demanda-se uma nova lógica operacional e organização, que passa a ser apresentada por meio da Industria 4.0, um modelo cujo a sua aplicação torna-se irreversível.

Os menores custos e a maior eficiência são resultados do processo em tempo real, digitalização e automatização de processos, planejamento preciso para otimização da execução, produção flexível, utilização inteligente dos recursos humanos e maior velocidade nas operações (Martins, 2018).

Segundo Silveira (2017) por ser uma nova proposta que demanda mão-de-obra qualificada e pelos altos custos para a implantação, pelo menos no Brasil, talvez a Indústria 4.0 demore para alcançar o setor industrial de forma considerável. Buscar meios para que as empresas principalmente de micro e pequeno porte possam utilizar e enquadrar-se nestas metodologias passa a ser um dos grandes desafios dos gestores.

Contudo, além dos desafios existentes na Indústria $4.0 \mathrm{com}$ as novas tecnologias, as empresas mostraram-se preocupadas em se tornarem mais competitivas, buscando melhorar o sistema produtivo com melhorias no processo, e se tornarem cada vez mais sustentáveis (Stock \& Seliger, 2016).

O Objetivo deste trabalho está em disseminar a aplicação das metodologias aplicadas na indústria 4.0, por mais simples que estas sejam, proporcionando as organizações um novo patamar tecnológico bem como humano.

\section{Referencial Teórico}

\subsection{O perfil das micro e pequenas empresas}

As micro e pequenas empresas são relevantes para a sociedade, pois movimentam o mercado, além de empregar significativa parte da mão de obra própria, de terceiros ou do próprio empresário. Essas empresas precisam estar em constante adaptação à dinâmica atual do mercado, considerando-se a legislação brasileira e as alterações constantes nas políticas tributárias (Santos \& Veiga, 2011).

Quanto as perspectivas atuais e futuras da gestão nas MPE's, Wanke e Magalhães (2016) argumentam que apesar de desempenharem um importante papel no contexto socioeconômico brasileiro, essas empresas têm um acesso escasso às ferramentas de administração, seja pela falta de padronização em suas operações, seja pelo empirismo excessivo dos seus dirigentes.

Elas são abrangidas pela LC n 123/2006, a qual dá tratamento diferenciado e favorecido para elas. Desde que não haja nenhuma atividade impeditiva, ambas podem optarem pela forma de tributação do Simples Nacional. Para as empresas optantes pelo Simples Nacional, há uma nova mudança no limite do faturamento a partir do ano de 2018. As micro empresas podem faturar até $\mathrm{R} \$ 360.000,00$ ao ano, já as pequenas empresas possuem o limite de $\mathrm{R} \$ 4,8$ milhões ao ano (Da Costa Mozzaquatro et. al, 2020).

Segundo Crnkovic e Moretti (2012), relatam que gerenciar uma empresa de pequeno porte exige um visão diferenciada e compreensão de suas especialidades, entre elas: legislação específica para abertura de MPE's, estruturas, 
sistemas de informação específicos, estratégias, habilidades e estilos administrativos.

De acordo com Sebrae (2019), "Em janeiro de 2019, os pequenos negócios geraram 60,7 mil empregos formais celetistas, sustentando uma vez mais a geração de empregos na economia. Para classificação das empresas quanto ao porte, foi utilizado o critério proposto pelo Sebrae (2019), que utiliza a classificação pela quantidade de pessoas ocupadas, ou seja, no comércio e serviços são classificadas como micro empresas aquelas que possuem até 09 colaboradores, como pequenas aquelas que possuem de 10 a 49 colaboradores, médias de 50 a 99 e grandes acima de 100.

A Finep (Financiadora de Inovação e Pesquisa) tem como um dos seus principais objetivos transformar o Brasil por meio da inovação para estimular o desenvolvimento social e econômico do país pelo fomento público. Suas prioridades se concentram nas Micro e Pequenas Empresas, oferecendo apoio através de financiamentos (crédito), investimentos e subvenção econômica (Henrique, 2020).

\subsection{Indústria 4.0}

Desde seu advento na Alemanhã em 2012 a Indústria 4.0 tem impactado acima de tudo a maneira de gerir as organizações bem como os negócios e as relações de trabalhos. De acordo com Souza e Gasparetto (2018) durante a história, a humanidade presenciou várias revoluções que moldaram o mundo atual, principalmente no que diz respeito aos sistemas econômicos e as estruturas sociais, desencadeadas pela inserção de novas tecnologias e maneiras distintas de compreender o mundo.

Segundo Stojkić, Veža e Bošnjak (2016) as três primeiras revoluções industriais resultaram da introdução de máquinas, eletricidade e informações tecnológicas, enquanto que a quarta Revolução Industrial: Indústria 4.0, é resultado da introdução da internet das coisas e serviços no processo produtivo.

A Indústria 4.0 é o resultado de vários estágios históricos da revolução industrial. No estágio da digitalização, a indústria conta com tecnologias de fabricação com alto nível de sofisticação, troca de dados e automação, influenciando o cenário industrial e a competitividade entre países. Sobre isso constata-se que "quanto maior o grau de digitalizados e em rede, os processos dentro das operações industriais, maior o desejo para mais interfaces em desenvolvimento, produção e vendas" (Balasingham, 2016).

No escopo da quarta revolução industrial, o uso de outras máquinas vem trazendo transformações que vão além do "chão de fábrica", mas permeiam todo o universo do consumidor e considera fatores importantes para a sustentabilidade do planeta, o que tem sido possível, dentre outros, por meio de quatro pilares principais (Schwab, 2018), quais sejam: big date, IOT (Internet das coisas), robótica e cloud computing.

Estabelecer os elementos de um conceito ainda em formação é tarefa bastante complexa. Sacomano et al (2018) apresenta uma proposta para classificar os elementos que são a base formadora da indústria 4.0. Entende-se que não é uma formação definitiva, mas tem um caráter didático e concreto, conforme Figura 1. 
Figura 1. A “Casada Indústria 4.0”.

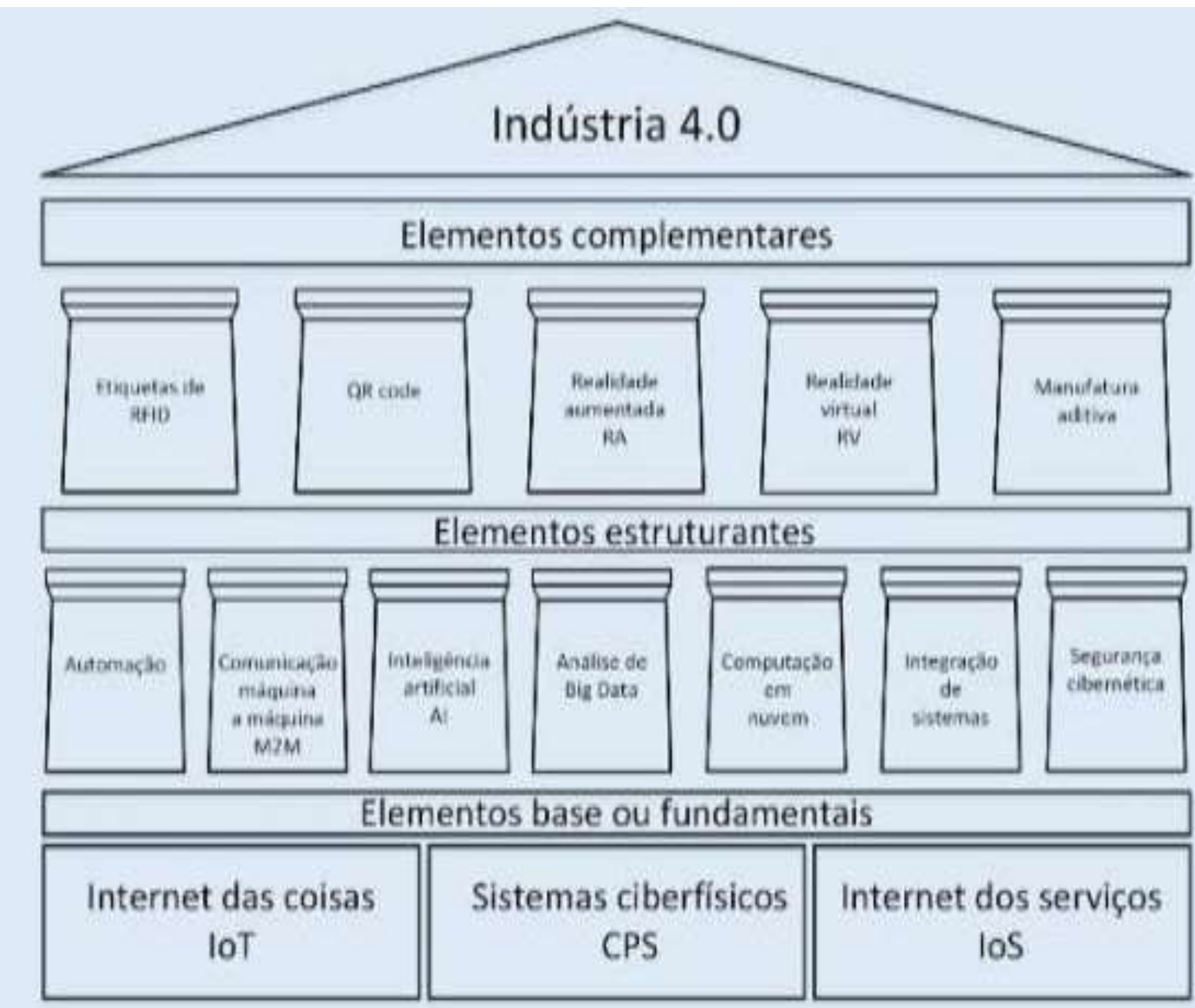

Fonte: Sacomano et.al (2018).

Segundo Rüßmannet et. al, (2015), a indústria 4.0 é sustentada por 9 pilares principais tecnológicos:

- Big data e análise de dados: grandes quantidades de dados sobre a manufatura obtidos de diversas fontes, como equipamentos de produção, sistemas de gestão de empresas e clientes, podem ser analisados e, assim, utilizados para a tomada de decisão em tempo real.

- Robôs autônomos: robôs já são utilizados na indústria, porém eles tendem a ser mais autônomos, podendo trabalhar ao lado dos humanos de forma segura, custando menos e tendo maiores capacidades.

- Simulação: a tomada de decisão poderá ser auxiliada pelas simulações, que utilizarão informações obtidas em tempo real. A otimização de parâmetros poderá ser feita a partir de testes de otimização, feitos com modelos virtuais.

- Integração de sistemas horizontal e verticalmente: sistemas estarão mais integrados, até mesmo em redes de intercompanhias, o que possibilitará maior automação.

- A Internet das Coisas Industrial: proporciona a interação entre os mais diversos equipamentos, conectando equipamentos com processamento embarcado, auxiliando a obtenção de respostas em tempo real.

- Segurança cibernética: a maior conectividade demandará maiores proteções contra-ataques cibernéticos, e, assim, impulsionará a construção de novas tecnologias para este fim.

- $\quad$ Nuvem: o uso da computação em nuvem, que já vem sendo utilizada em aplicações empresariais e análise de dados, aumentará com a indústria 4.0, contribuindo para ganhos em performance das tecnologias envolvidas, auxiliando 
questões entre companhias.

- $\quad$ Fabricação de aditivos: a indústria 4.0 possibilitará a construção de produtos customizados de forma descentralizada, reduzindo despesas com estoque, a partir do uso de tecnologias como as impressoras 3D.

- $\quad$ Realidade aumentada: a tomada de decisão e o desenvolvimento de procedimentos serão auxiliados pela realidade aumentada, que suporta uma grande variedade de sistemas.

\subsection{Utilização da impressão 3D}

A técnica da impressão 3D consiste na utilização de impressoras de prototipagem rápida que têm a função de desenvolver protótipos de produtos no menor tempo possível, tendo como vantagem sobre as máquinas tradicionais a dispensa do uso de ferramental e a diminuição dos custos de produção (Da Cruz Ferreira, Krüger \& Dos Santos, 2016).

A principal função das impressoras 3D consiste na confecção de objetos sólidos de forma rápida, por meio de manufatura aditiva de deposição de partículas menores, com eliminação de ferramentas customizadas de produção, redução de custo e tempo, uma vez que o processo tradicional demanda tempo e pode ocorrer falhas no processo de manufatura (Wu et al ,2016).

Para Abreu et al. (2017) definem que a simulação se trata de uma técnica baseada no desenvolvimento de um modelo de objeto ou processo. A realização de uma simulação permite uma visão mais ampla do objeto em estudo, tornando mais eficiente a análise de custo-benefício e tempo de produção.

A modelagem tridimensional surgiu entre o final dos anos 80 e início dos anos 90, ganhando espaço no mercado por ser uma técnica viável e que traz retornos rápidos. Esta técnica consiste na obtenção de formas tridimensionais de qualquer tipo de objeto através de uma representação matemática feita em softwares computacionais (Volpato et al., 2007).

A técnica da modelagem tridimensional permite a realização de projetos personalizados de produtos, o que facilita $o$ atendimento das necessidades de cada cliente individualmente, tanto no que diz respeito às especificações, quanto a design inovador e utilização de uma variedade de materiais para a fabricação (Hausman \& Horne, 2014).

\subsubsection{Manufatura Aditiva}

A Manufatura Aditiva trata-se de um processo de fabricação baseado na adição de material em diversas camadas planas aplicadas diretamente a partir de fontes de dados, onde estes são fornecidos por sistemas de projeto auxiliado por computador, ou seja, a utilização do processo de impressão 3D, por meio deste advento varias mudanças relevantes nas estruturas produtivas convencionais serão inseridas com a finalidade da fabricação direta de produtos (Gorni, 2007).

Um dos grandes diferenciais em relação a outros processos já que a tecnologia não requer ferramentas especiais para fixação ou moldes, os protótipos são obtidos em menor tempo sem a necessidade de cálculos de geometrias e trajetória de movimento da máquina (Outrossim, Volpato et al., 2007).

A inserção de impressoras 3D de baixo custo no mercado tem possibilitado a propagação de produção de pequenos lotes e economicamente viáveis, além de proporcionar várias interações nos processos (Barifouse et. al, 2012).

A Figura 2 apresenta o processo de interação de alguns itens que podem ser trabalhados neste processo, proporcionando uma elevação no patamar da organização, seja em seus processos produtivos como também no conhecimento adquirido pelas pessoas que atuam nesta metodologia. 
Figura 2. Interação no processo de impressão 3D.

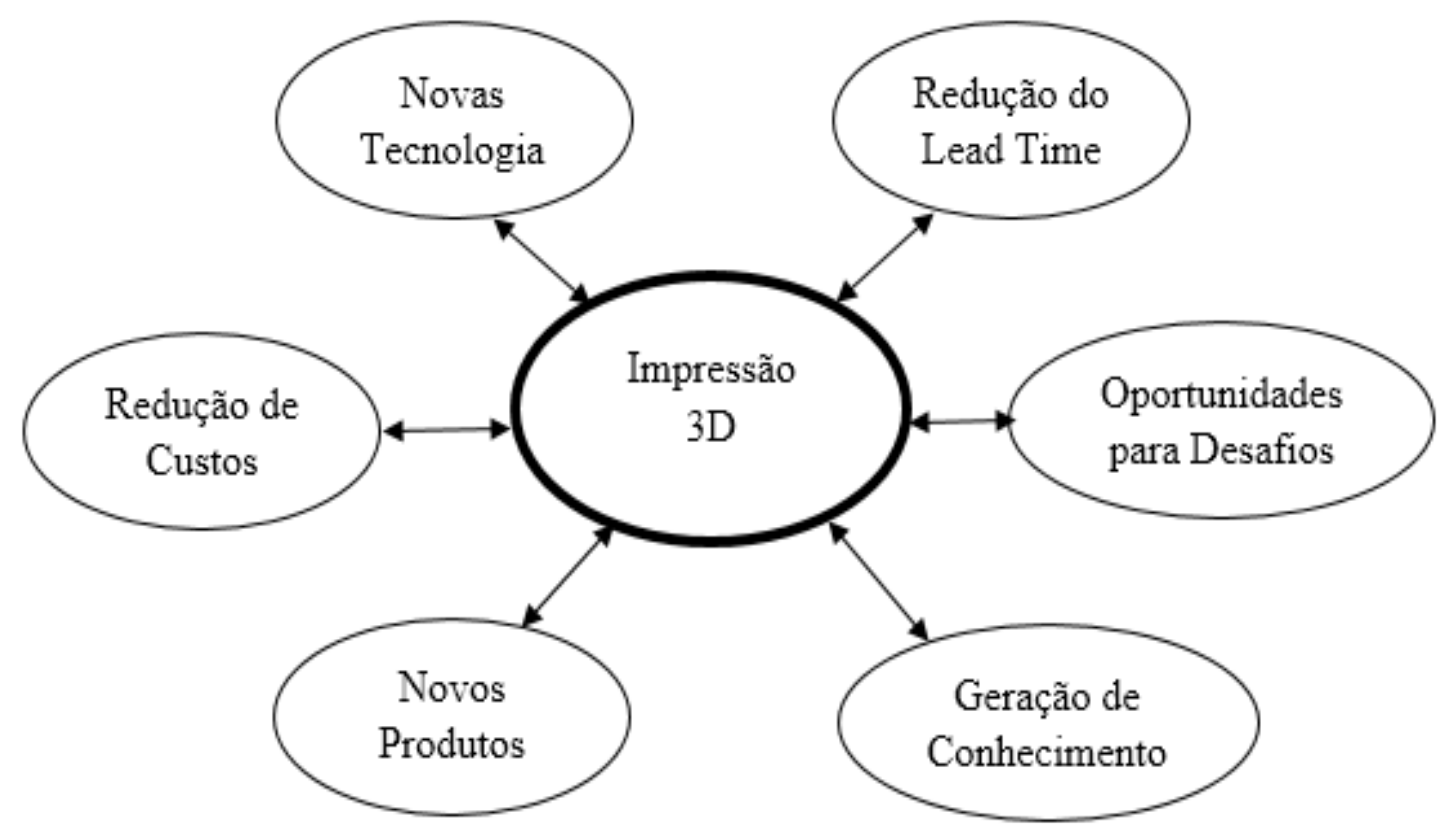

Fonte: Autores (2021).

A Figura 2 apresenta algumas das possíveis interações entre o processo de impressão 3D nas organizações, criando e potencializando oportunidades nas tomadas de decisão dentro das empresas, como está é apenas uma das várias metodologias aplicadas na indústria 4.0 quanto maior forem as combinações com as outras ferramentas estas decisões acabam sendo exponencializadas, fazendo com que se obtenha melhores resultados não somente operacionais mais também financeiros promovendo a empresa junto aos seus clientes e a novos mercados.

\subsection{A interface entre as Micro e Pequenas Empresas e a indústria 4.0}

Para as Micro e Pequenas Empresas muitas vezes há um grande distanciamento no uso das tecnologias em parte grande por questões financeiras uma vez que estas novas tecnologias ainda apresentam um custo muito elevado, não somente de maquinário como também de mão de obra. Outro aspecto, é que a presença de restrições tecnológicas e de know-how podem dificultar a entrada de novos concorrentes em vários mercados e muitas indústrias poderão optar por fusões ou estabelecer parceria na busca pela continuidade do negócio. Na outra ponta da cadeia, a integração com fornecedores também poderá ser aprimorada (Porter \&Heppelmann, 2014).

Porém algumas destas tecnologias já estão bem praticáveis e a custos acessíveis o que permite a inclusão destas empresas na era 4.0. As novas redes de valor podem ser construídas para compartilhar o conhecimento e a tecnologia, o que poderá beneficiar principalmente micro e pequenas empresas, ao promover a incorporação de ferramentas, tecnologias e metodologias (Kagermann et al, 2013).

Diante disso, Hermann et al (2015) buscaram compreender os principais componente-chave que, quando combinados durante suas operações, promovem a implementação da Indústria 4.0. Os resultados são classificados como: sistemas ciberfísicos, "Internet das Coisas", "Internet dos Serviços" e "Fábricas Inteligentes”.

As novas relações com as metodologias 4.0 devem ser cada vem mais frequentes entre as MPE's, estimulando assim o crescimento organizacional e das pessoas envolvidas. Dessa forma, a sua adaptação para a Indústria 4.0 será cada vez mais abrangente e acessível e sua difusão poderá ser ilimitada. 


\section{Metodologia}

Nesta seção, serão descritos os procedimentos metodológicos que nortearam o desenvolvimento deste trabalho. Para Gil (2010) o estudo de caso passa a ser uma estratégia de estudo intenso e extenuante de pessoas, grupos ou instituições em particular, de modo a permitir seu amplo e detalhado conhecimento. Também foi utilizado o método dedutivo para obtenção de respostas.

Segundo Araújo (2000), o método dedutivo é descrito como um caminho para alcançar retornos, do geral para o particular, a partir de análises de fontes de trabalhos para conseguir uma conclusão.

Diante disso, esta pesquisa teve como abordagem qualitativa, utilizando como proveniência, universos de significados, motivos e crenças, na busca de uma concepção mais minuciosa de significados (Lakatos \& Marconi 2010).

Para delineamento das respostas, a coleta de informações, foi realizada por meio de entrevistas, e observações com os responsáveis pelo processo produtivo da organização. Gil (2010) descreve que entrevista é um procedimento formal entre duas ou mais pessoas para obter respostas sobre determinados questionamentos.

Para apuração dos dados coletados foi aplicado a analise descritiva, permitindo determinar o fenômeno ou a afirmação de relação entre as possíveis variáveis procurando relacionar as ações teóricas com as práticas executadas (Gil, 2010).

\section{Resultados e Discussão}

A empresa "SOCRAM" fundada em julho de 2001 situada na região metropolitana de São Paulo, atua no ramo de elementos de fixação (tirantes, parafusos, porcas, arruelas, prisioneiros entre outros) para indústria. Conta com cerca de 80 colaboradores sendo 62 destes no setor fabril.

Foram entrevistados os responsáveis pelo processo produtivo e pelo setor fabril da empresa, no período de novembro de 2020.

Após a reestruturação realizada na organização a fim de se tornar uma empresa mais competitiva no mercado e atraente para os seus clientes, para os entrevistados foram nítidas as mudanças realizadas pela organização bem como o retorno dos seus colaboradores frente a estas mudanças. Com a determinação da alta direção da empresa de enquadrar a organização como uma indústria 4.0 novos equipamentos foram comprados e novos colaboradores foram contratados. O Quadro 1 identifica o perfil dos entrevistados.

Quadro 1. Perfil dos entrevistados.

\begin{tabular}{|c|c|c|}
\hline \multicolumn{3}{|c|}{ Perfil dos entrevistados } \\
\hline Cargo & Setor & Entrevistado \\
\hline Diretor Industrial & Fábrica & 1 \\
\hline Gerente Produção & Produção & 2 \\
\hline
\end{tabular}

Fonte: Autores (2021).

Para os entrevistados as metodologias 4.0 estão relacionados diretamente com novos produtos, máquinas automatizadas e alta produtividade, não tendo como dissociar a inovação tecnológica de uma empresa que se caracterize como indústria 4.0. A inovação tecnológica para ambos também está ligada ao baixo custo, gestão de informação e a melhorias de processos e de qualificação pessoal. Segundo os entrevistados este conjunto de fatores traz para a organização uma vantagem competitiva importante. 
A organização está em contínuo crescimento para criação de novos produtos, tendo como base as necessidades dos clientes, maior rendimento da produção global e, por consequência, maiores lucros.

A empresa desenvolve os seus protótipos de como convêncional ou seja usinando os seus modelos em máquinas operatrizes, passa também a utilizar a impressão 3D como complemento na aplicação de alguns de seus produtos. Foram escolhidos peças mais simples de baixa complexidade para a construção uma vez que este processo é experiental para a empresa, com isso minimizando riscos e proporcionando ganho de experiência para os envolvidos.

Algumas peças como arruelas, encaixes para rolamentos, rampas de alinhamentos e suportes para base de alinhamento foram os produtos escolhidos para serem feitos no conceito da manufatura aditiva. O Quadro 2 identifica os itens a serem confeccionados na impressora 3D.

Quadro 2. Descrisão dos produtos.

\begin{tabular}{|l|l|}
\hline \multicolumn{1}{|c|}{ Descrisão do produto } & Produto \\
\hline Arruelas & \\
\hline Encaixes para rolamentos & \\
\hline Rampas de alinhamentos & \\
\hline Suportes para base de alinhamento & \\
\hline
\end{tabular}

Fonte: Autores.

O Quadro 2 ilustra os produtos a serem realizados pelo processo de impressão 3D proposto onde, uma vez armazenado as informações torna-se possível repeti-lás quantas vezes for necessárias, fazendo com que o processo seja cada vez mais estável, reprodutiveis e confiáveis.

Também serão construídas algumas peças de reposição de algumas máquinas utilizadas internamente como componentes que não são mais fabricados e precisam ser adaptados, ou até mesmo peças faltantes de reposição e manutenção para os mesmos no mercado e no estoque. Com isso também pretende-se reduzir o lead time de algumas peças que são adquiridas de terceiros e que o tempo de entrega não atenda as necessidades da empresa.

\subsection{Metodologias 4.0 segundo os entrevistados}

Para o entrevistado 1 torna-se de extrema relevância a aplicação e utilização das metodologias 4.0, onde a interação entre os departamentos fazem parte integrante para o atendimento das metas estipuladas pela organização. Integrar os departamentos permitirá reduzir custos, aumentar o desempenho organizacional tornando a empresa mais flexível e dinâmica.

Conforme relatado pelo entrevistado 2 identificar e aplicar estas metodologias eleva o patamar da organização, mesmo que a princípio seja uma aplicação mais simples, porém é um importante passo para implementação de novos elementos aliados a indústria 4.0 potencializando a demanda organizacional. 
A implementação de métodos e equipamentos como impressora 3D torna por exemplo a execução de protótipos mais rápidos permitindo assim demonstrar ao cliente como ficará o seu produto final, seja ele um anel elástico, uma arruela de pressão ou mesmo um disco de fixação, salienta o entrevistado 1 .

Ainda segundo a entrevistada 2 a empresa deve desenvolver seus produtos, processos e/ou serviços com a mesma eficiência e eficácia independentemente da quantidade solicitada pelo cliente, uma vez que a flexibilidade em sua linha de produção passa a ser o diferencial em relação aos seus concorrentes.

Ambos concordam que eficiência e eficácia juntamente com a flexibilidade passa a ser a palavra de ordem para uma organização que pretende se enquadrar no conceito da 4.0 e ainda cabe a organização também ter o papel integrador entre homem e máquina, potencializando assim os resultados esperados.

\subsection{Visão estratégica segundo os entrevistados}

Ambos os entrevistados acreditam que com a utilização do processo deimpressão 3D, uma nova cultura surge dentro da organização permitindo assim uma nova visão também pelos colaboradores.

Para o entrevistado 1 a utilização desta metodologia possibilita a criação de novos caminhos para a organização, e até mesmo novos mercados uma vez que se torna possível imprimir "tudo", obtendo bons resultados e principalmente com maior agilidade operacional.

Segundo o gerente de produção entrevistado $2 \mathrm{o}$ impacto nas estratégias de produção passam a ser praticamente em tempo real o que auxilia na tomada de decisão no dia a dia da organização e principalmente no que diz respeito as ações corretivas solicitadas pelos clientes em seus produtos, onde torna-se possível a visualização e construção do produto físico e não somente na tela do computador como era realizado anteriormente, agregando valor a todos os processos envolvidos.

\subsection{Novos desafios para as Micro e Pequenas Empresas}

Para os entrevistados estes concordam que as implementações das metodologias 4.0 são um processo irreversível e que deve ser absorvido o mais rápido possível pelas organizações e também pelos colaboradores, uma vez que a atualização profissional também é parte integrante deste processo seja ele em menor ou maior escala.

Ainda para o entrevistado 2 todo o processo de mudança deve romper possíveis paradigmas, assim como as pessoas envolvidas devem estar propensas a realização do novo, sendo que este trará benefícios para todos dentro e fora da organização.

Já para o entrevistado 1 a implantação e implementação de tecnologias da Indústria 4.0, têm potencial de melhoria na produtividade nas indústrias em especial as de micro e pequeno porte, uma vez que quarquer tipo de mudança por menor que seja afeta diretamente toda a cadeia produtiva. As novas tecnologias devem facilitar e auxiliar na produção de novos itens o que permite um impacto relevante nas micro e pequenas empresas, principalmente no seu faturamento.

\section{Conclusão}

A implementação das metodologias da Indústria 4.0, não apenas traz um processo inovativo os setores produtivos industriais, como também se apresenta como uma das possíveis saídas para a busca de maiores produtividades e consequentemente maiores lucros operacionais por meio da conectividade, onde romper paradigmas passa a permitir uma maior flexibilização e autonomia de controle das organizações operacionais.

Independentemente do porte da empresa ou de seu segmento torna-se extremamente relevante a busca por novos conhecimentos bem como nas aplicações das ferramentas referenciadas como base da Indústria 4.0,

Envolver sobre tudo a mudança de mentalidade com vistas as tecnologias emergentes fazem com que as micro e 
pequenas empresas possam alcançar patamares cada vez maiores. Diante deste cenário outro fator importante está relacionado com as tomadas de decisão que passam a ser cada vez mais acertivas e rápidas potencializando o desempenho da organização.

O presente trabalho buscou e apresentou de maneiras consistentes de ser enquadrar uma empresa de micro e pequeno porte na denominada indústria 4.0 pelo uso da ferramenta de impressão 3D, que embora de certa simplicidade pode ser um fomentador de novas tecnologias, demonstrando para os envolvidos sejam eles seus colaboradores assim como seus clientes que é possível inovar e utilizar as tecnologias disponíveis.

Esse estudo é apenas o início de uma pesquisa relacionada a utilização das metodologias 4.0 nas micro e pequenas empresas. As contribuiões com novas pesquisas podem promover o avanço desta utilização em outras organizações.

\subsection{Trabalhos futuros}

$\checkmark$ Análise de empresas de serviços que utilizam as metodologias 4.0 e quais os seus resultados.

$\checkmark$ Como a implementação de novas tecnologias pode afetar os colaboradores a curto e médio prazo.

\section{Agradecimentos}

Aos nossos familiares pelo apoio, carinho e compreensão.

\section{Referências}

Abreu, C. E. M., Gonzaga, D. R. B., dos Santos, F. J., de Oliveira, J. F., de Morais Oliveira, K. D., Figueiredo, L. M., \& dos Santos Gonçalvesa, G. A. (2017). Indústria 4.0: Como as empresas estão utilizando a simulação para se preparar para o futuro. Revista de Ciências Exatas e Tecnologia, 12(12), 49-53.

Araujo, S. C. C. D. (2000). Métodos de pesquisa. Universidade Católica de Brasília.

Balasingham, K. (2016). Industry 4.0: securing the future for German manufacturing companies (Master's thesis, University of Twente).

Barifouse, R., Coronato, M., \& Ciscati, R. A nova revolução industrial muda à forma como os objetos são criados, produzidos e consumidos. Revista Época, http://revistaepoca.globo.com/Ciencia-e-tecnologia/noticia/2012/10/novarevolucao-industrial-muda-forma-como-os-objetos-sao-criados-produzidos-econsumidos.html.

Crnkovic, L. H., \& do Amaral Moretti, S. L. (2012). Gestão de micro e pequenas empresas: uma proposta de disciplina para a formação do engenheiro. Revista Gestão da Produção Operações e Sistemas, (4), 11.

da Costa Mozzaquatro, P., Camargo, B. F., Guze, J. C., dos Santos, L. A., Zanatta, J. M., \& Halberstadt, I. A. (2020). Controles de departamento pessoal de micro e pequenas empresas: uma análise de empresas da região central do Rio Grande do Sul. Research, Society and Development, 9(8), e752986132e752986132.

da Cruz Ferreira, G., Krüger, T. R., \& dos Santos, C. B. (2016). Utilização da impressão 3d na manufatura para a otimização de processos: um estudo de caso em indústrias automobilísticas. Memorial TCC Caderno da Graduação, 2(1), 276-289.

Gil, A. C. (2010). Como elaborar projetos de pesquisa. Atlas. Como elabora projetos de pesquisa. (5a ed.), Atlas.

Hausman, K. K., \& Horne, R. (2014). 3D printing for dummies. John Wiley \& Sons.

Henrique, T. D. A. (2020, December). A Relação Entre Investimentos Em Inovação E O Crescimento Das Micro E Pequenas Empresas. In XVI Jornada de Iniciação Científica e X Mostra de Iniciação Tecnológica-2020.

Hermann M. et al. (2015) Design Principles for Industrie 4.0 Scenarios: A Literature Review,

Kagermann, H., Wahlster, W., \& Helbig, J. (2013). Recommendations for implementing the strategic initiative Industrie 4.0: Final report of the Industrie 4.0 Working Group. Forschungsunion: Berlin, Germany.

Lakatos, E. M., \& Marconi, M. de A. (2010). Fundamentos de metodologia científica (5a ed.). Atlas.

Martins, N. F. S. (2018). Estudo das vantagens da aplicação de metodologias, indústria 4.0, no contexto industrial (Doctoral dissertation).

Piana, J., \& Erdmann, R. H. (2011). Fatores geradores de competitividade na manufatura: uma relação entre práticas e resultados. Revista de Administração da Universidade Federal de Santa Maria, 4(1), 73-90.

Porter, M., Heppelmann, J. (2014) A gestão da internet das coisas. Harvard Business Review, Novembro. Extraído de http://www.hbrbr.com.br/comoprodutos-inteligentes-e-conectados-estao-transformando-a-competicao.

Rüßmann, M., Lorenz, M., Gerbert, P., Waldner, M., Justus, J., Engel, P., \& Harnisch, M. (2015). Industry 4.0: The future of productivity and growth in manufacturing industries. Boston Consulting Group, 9(1), 54-89. 
Research, Society and Development, v. 10, n. 1, e56710112218, 2021 (CC BY 4.0) | ISSN 2525-3409 | DOI: http://dx.doi.org/10.33448/rsd-v10i1.12218

Sacomano, J., \& Sátyro, W. (2018). Indústria 4.0: conceitos e elementos formadores. EDGARD BLUCHER LTDA.(Org.). Indústria, 4 , 27-47.

Santos, B. P., Alberto, A., Lima, T. D. F. M., \& Charrua-Santos, F. M. B. (2018). Indústria 4.0: desafios e oportunidades. Revista Produção e Desenvolvimento, 4(1), 111-124.

Santos, F. D. A., \& Veiga, W. E. (2014). Contabilidade com ênfase em micro, pequenas e médias empresas. Atualizado pela legislação até Fevereiro de.

Schwab, K., \& Davis, N. (2019). Aplicando a quarta revolução industrial. Edipro.

Serviço Brasileiro de Apoio às Micro e Pequena Empresas -Sebrae (2019). Análise do CAGED.

Silveira, C. B., \& LOPES, G. C. (2018). O que é Indústria 4.0 e como ela vai Impactar o mundo.

Souza, E. S. D. (2018). Características e impactos da indústria 4.0: percepção de estudantes de ciências contábeis.

Stock, T., \& Seliger, G. (2016). Opportunities of sustainable manufacturing in industry 4.0. Procedia Cirp, 40, 536-541.

Stojkić, Ž. Veža, I., \& Bošnjak, I. (2016). A Concept of Information System Implementation within Industry 4.0. Vienna, Áustria: DAAAM International. http://bib.irb.hr/datoteka/830369.127.pdf.

Volpato, N. (2007). Prototipagem rápida: tecnologias e aplicações. Editora Blucher.

Wanke, P. F., \& Magalhães, A. (2000). Logística para micro e pequenas empresas. Editora Atlas SA.

Wu, P., Wang, J., \& Wang, X. (2016). A critical review of the use of 3-D printing in the construction industry. Automation in Construction, 68, 21-31. 